\title{
(2) OPEN ACCESS \\ Fever in a patient with osteomyelitis: the diagnosis could be serotonin syndrome
}

\author{
Matthew Gould, ${ }^{1}$ William D Harrison, ${ }^{2}$ Abbey Cahill-Kearns, ${ }^{3}$ Greg Barton ${ }^{3}$
}

\begin{abstract}
${ }^{1}$ Acute Medicine, St Helens and Knowsley Teaching Hospitals NHS Trust, Prescot, UK ${ }^{2}$ Orthopaedics, Health Education North West, Liverpool, UK ${ }^{3}$ Intensive Care, St Helens and Knowsley Teaching Hospitals NHS Trust, Prescot, UK
\end{abstract}

\section{Correspondence to} Dr Matthew Gould; matthew.gould@doctors.org.uk

Accepted 30 December 2020

A Check for updates

(c) BMJ Publishing Group Limited 2021. Re-use permitted under CC BY-NC. No commercial re-use. See rights and permissions. Published by BMJ.

To cite: Gould M Harrison WD, Cahill-Kearns A, et al. BMJ Case Rep

2021:14:e239152

doi:10.1136/bcr-2020-

239152

\section{SUMMARY}

Awareness of rare differential diagnoses of common clinical presentations helps promote early detection and prompt management of serious conditions. A 54-yearold man, with an infected non-union following a high tibial osteotomy, presented with an acutely discharging abscess to his proximal tibia. He was generally unwell with a Staphylococcus aureus bacteraemia. The tibia was debrided, CERAMENT G used as dead space management and a spanning external fixator applied. Postoperatively, pregabalin and tapentadol were commenced in addition to amitriptyline and sertraline, which the patient was taking regularly. Overnight, the patient developed hyperthermia, inducible clonus, hyperreflexia, agitation, confusion and rigors. Prompt recognition of the possibility of serotonin syndrome resulted in early cessation of serotonergic medications and a positive outcome. From this case an important message is that fever in a patient taking serotonergic medications should prompt a screening neurological examination. Clinicians should also be wary when patients are commenced on multimodal analgesia, including tapentadol.

\section{BACKGROUND}

An awareness of rare differential diagnoses of common clinical presentations helps promote the early detection and prompt management of serious conditions. The following case report describes the presentation of serotonin syndrome postoperatively on an orthopaedic ward, which with prompt diagnosis was managed effectively with good outcomes for the patient.

Serotonin syndrome is a rare, unpredictable and potentially fatal cause of fever. It is a drug-induced condition caused by too much serotonin within the synapses of the nervous system. Generally, it results from the combination of at least two drugs that increase serotonin levels or sometimes an overdose with a single drug that raises serotonin. ${ }^{1}$ Its incidence among 15 million patients in the USA who were taking serotonergic agents was around $0.07 \%$ to $0.19 \% .^{2}$ The true incidence of serotonin syndrome is thought to be unknown, due to it being under-recognised and under-reported. ${ }^{3}$

Currently, the Hunter Serotonin Toxicity Criteria ( $84 \%$ sensitive and $97 \%$ specific) is the most widely accepted diagnostic tool, with an emphasis on the following signs in the presence of a serotonergic agent: spontaneous or inducible clonus, agitation, tremor, diaphoresis, ocular clonus, hypertonia, hyperthermia and hyperreflexia (figure 1). ${ }^{4}$ The critical management step following diagnosis is identification and discontinuation of causative agents. In severe cases complications can include seizures, disseminated intravascular coagulopathy, metabolic acidosis, rhabdomyolysis, renal failure and death. Consequently patients with more severe cases may require management in critical care. ${ }^{5}$

\section{CASE PRESENTATION}

A 54-year-old man presented with an acutely discharging sinus with abscess to his right proximal tibia on the background of a complex orthopaedic history involving an infected non-union from an elective right tibial osteotomy. Past medical history included well-controlled asthma, obstructive sleep apnoea, hypertension, deep vein thrombosis and pericarditis.

At presentation, the patient was generally unwell with swinging fever and was found to have a Staphylococcus aureus bacteraemia. He was started on flucloxacillin intravenously and an echocardiogram requested.

Right knee radiographs showed non-union of the proximal tibia and evidence of a sequestrum, confirmed by CT scan. Right tibial exploration and debridement was conducted with tissue sampling, instillation of CERAMENT G (antibiotic laden synthetic bone substitute) and application of a spanning external fixator. All six tissue samples grew methicillin-sensitive S. aureus, with Proteus mirabilis and Enterobacter growing in one tissue sample.

Following the operation, oral rifampicin was added. A transthoracic echo showed an echogenic mobile structure behind the mitral valve leaflet, which was queried as an endocarditis vegetation. Flucloxacillin was increased to six times per day.

Postoperative complications included significant pain and acute kidney injury stage III, the latter deemed secondary to hypovolaemia and improved following intravenous fluid administration. The episodes of fever had resolved at this stage.

On the $5^{\text {th }}$ day after the operation, following a difficult night with pain, $75 \mathrm{mg}$ pregabalin (given two times per day) and subsequently $100 \mathrm{mg}$ tapentadol modified release (given every 12 hours) were commenced for analgesia. The pregabalin was later increased to $150 \mathrm{mg}$ (given two times per day). This was in addition to $25 \mathrm{mg}$ amitriptyline (given one time per day), $150 \mathrm{mg}$ sertraline (given one time per day) and $20 \mathrm{mg}$ ketamine (given up to four times per day as required) which the patient was already taking.

The following day the patient deteriorated, and the initial impression was of sepsis secondary to tibial infection and/or infective endocarditis. However, following a review of the patient's 


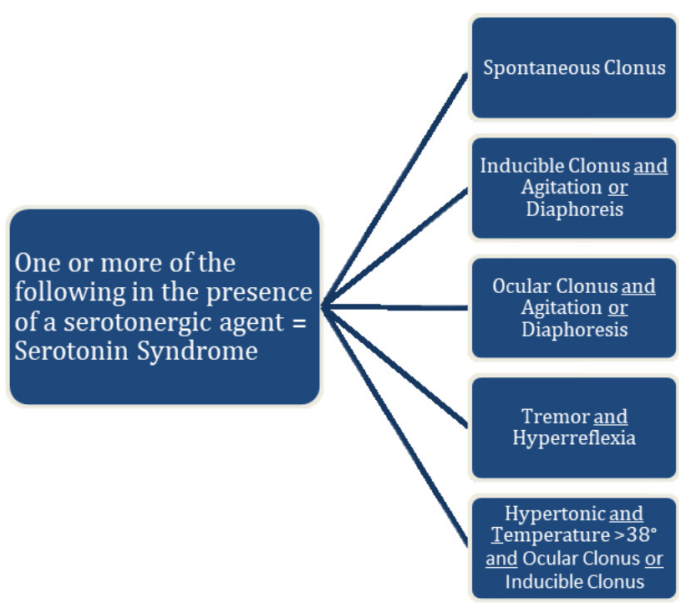

Figure 1 The Hunter Serotonin Toxicity Criteria (adapted).

medications, the possibility of serotonin syndrome was raised, as it was noted that he had been commenced on tapentadol (one dose given) and pregabalin within the previous 48 hours and was already taking sertraline and amitriptyline. On examination he had hyperthermia $\left(41^{\circ} \mathrm{C}\right.$ at highest), tachycardia and tachypnoea. The patient also had neurological findings of tremor, hyperreflexia, agitation and bilateral inducible ankle clonus. These findings in the context of his recent medication history, supported a diagnosis of serotonin syndrome. Therefore, all serotoninergic medications were suspended and critical care involvement was requested.

The patient was admitted to the critical care unit for careful monitoring. Blood cultures that were taken at the time of the initial temperature rise grew P. mirabilis. Meropenem was added and flucloxacillin increased to every four hours. The patient's creatine kinase (CK) rose to $6490 \mathrm{U} / \mathrm{L}$ over the next few days. The patient did have some tenderness to the mid anterior thigh and an urgent MRI of the right thigh ruled out myositis as a cause of the rising CK.

Vital and neurological signs settled after cessation of the medications in question, with the last significant temperature rise of $39.5^{\circ} \mathrm{C}$ recorded around 72 hours from the initial clinical deterioration. On day 7 the patient's CK had dropped to $205 \mathrm{U} / \mathrm{L}$. The patient was stepped down to the ward and avoided requiring any level 2 or 3 interventions. A transoesophageal echo, conducted when the patient was discharged from the intensive care unit, concluded that there were no criteria present for infective endocarditis and the previously reported abnormality was not significant.

\section{INVESTIGATIONS}

Laboratory investigations at that time showed a C-reactive protein (CRP) of $276 \mathrm{mg} / \mathrm{L}$ (which rose to $354 \mathrm{mg} / \mathrm{L}$ ), a white cell count (WCC) of $7.8 \times 10^{9} / \mathrm{L}$, neutrophils of $6.7 \times 10^{9} / \mathrm{L}$, lymphocytes $0.6 \times 10^{9} / \mathrm{L}$, creatinine $138 \mu \mathrm{mol} / \mathrm{L}$ and an alkaline phosphatase of $138 \mathrm{U} / \mathrm{L}$.

\section{DIFFERENTIAL DIAGNOSIS}

With the preceding history of $S$. aureus bacteraemia, possible infective endocarditis and a positive blood culture for P. mirabilis, the initial diagnosis, considered following the patient's deterioration postoperatively, was sepsis. Indeed, he was concomitantly treated as sepsis during his stay on the critical care unit, with an escalation of antibiotic therapy.

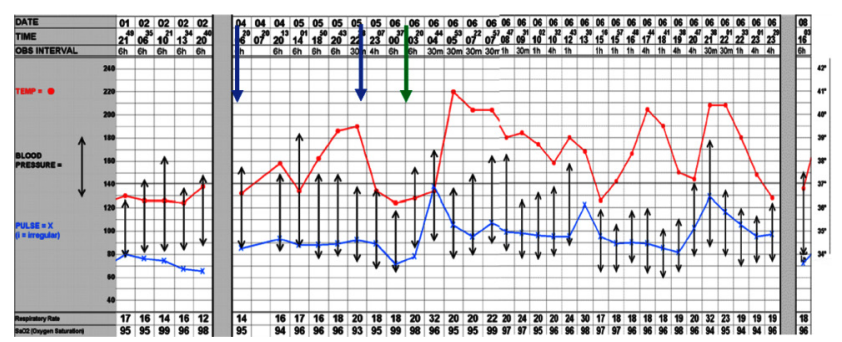

Figure 2 Patient's vital signs leading up to intensive care unit admission. Pregabalin was started at a dose of $75 \mathrm{mg}$ two times per day (BD) (blue arrow) and increased to $150 \mathrm{mg} \mathrm{BD}$ (second blue arrow). A single dose of tapentadol was given (green arrow).

The ultimate diagnosis of serotonin syndrome was first suspected due to the rapid deterioration following commencement of tapentadol and pregabalin (figure 2), alongside the examination findings present at this time, most notably the substantial hyperthermia of up to $41^{\circ} \mathrm{C}$, inducible clonus, confusion, agitation and hyperreflexia. The combination of agitation and inducible clonus, in the presence of serotonergic medications, confirmed the clinical diagnosis of serotonin syndrome as per the Hunter classification system. ${ }^{4}$ Laboratory results also illustrated a raised CRP without any raise in WCC or neutrophils to suggest an overwhelming bacterial infection was present.

Neuroleptic malignant syndrome (NMS) and malignant hyperthermia $(\mathrm{MH})$ both also cause a drug-induced hyperthermia. Within this case NMS was effectively ruled out on the basis that the patient was not taking any anti-dopaminergic medications. ${ }^{6}$ With $\mathrm{MH}$, the presentation would have been perioperatively or immediately postoperatively had a volatile anaesthetic agent or the depolarising muscle relaxant succinylcholine been used. ${ }^{7}$

\section{OUTCOME AND FOLLOW-UP}

The patient was discharged on a 6 -week course of antibiotics. In the past 6 months he underwent a further orthopaedic procedure on the right knee and currently has a circular fixator in place. There have been several pin site infections, ongoing issues with pain and an episode of deep vein thrombosis in the right leg. Currently, he is walking, fully weight bearing on his leg with the help of crutches and has been listed for removal of the external fixator and application of a cast.

\section{DISCUSSION}

Serotonin is synthesised from the essential amino acid tryptophan in both the midline raphe nuclei of the brainstem and enterochromaffin cells of the gastrointestinal (GI) tract. ${ }^{8}$ Around $40 \%$ to $80 \%$ of the body's serotonin is stored in the enterochromaffin cells of the GI tract, with the remainder found in the central nervous system and also on platelets. ${ }^{8}$ Within the central nervous system and GI tract serotonin has numerous functions including attention, affective behaviour, thermoregulation, motor tone, GI motility, vasoconstriction, bronchoconstriction and platelet aggregation. ${ }^{9}$ Serotonin syndrome is the clinical manifestation of over activation of these central and peripheral serotonin receptors. ${ }^{9}$

Serotonin syndrome typically occurs when two or more drugs that elevate serotonin are used together, especially if they elevate serotonin in different ways. ${ }^{1}$ Monoamine oxidase inhibitors (MAOI) carry the highest risk profile due to their action to slow the breakdown of serotonin by blocking monoamine oxidase. ${ }^{1}$ Serotonin reuptake inhibitors (SSRI, such as sertraline in this case) and serotonin-norepinephrine reuptake inhibitors 
(SNRI) carry the next most significant risk due to their action to prevent the reuptake of serotonin from synapses. ${ }^{1} \mathrm{~A}$ combination of an MAOI with another MAOI or an SSRI or SNRI is the most dangerous combination of drugs and most likely to result in serotonin syndrome. ${ }^{9}$ Tricyclic antidepressants (such as amitriptyline in this case), opioids, drugs of abuse and selected other prescription and herbal drugs also carry a significant risk profile. ${ }^{9}$

Within this case, the initial episode of fever developed following initiation of pregabalin (figure 2), with the patient already regularly taking sertraline and amitriptyline, before a more significant deterioration overnight following the single dose of tapentadol. It is possible that this initial fever was due to sepsis. The blood culture taken around this time grew P. mirabilis, which was also present on a single tissue sample taken operatively. Pregabalin in the literature is not thought to have any effect on serotonin receptors or any inhibition of serotonin reuptake. ${ }^{10}$ However three case reports were identified where initiation of pregabalin was thought to have resulted in serotonin syndrome. ${ }^{11-13} \mathrm{~A}$ small double blind randomised controlled trial has also shown that gabapentin, an analogue of pregabalin, increases serotonin

\section{Patient's perspective}

In 2018 I had a routine HTO (high tibia osteotomy) on my right leg to correct my stance due to knee pain. I was informed that I was too young to have a knee replacement and that this operation would solve my problem. Unfortunately, some 2 years later I am still using crutches to get around and have a metal fixator from above the knee down to my ankle.

In 2019, I had severe pain in my leg, swelling and redness so I took myself to A\&E. I was admitted and put in a single room. From that time, I cannot remember that much. I know I was hallucinating, and I was feeling irritable and restless. My wife recalls that I was asking all sorts of random questions. I was having extreme hot sweats and high temperatures. It is all quite hazy but my son, who works for our family business, had some amount of verbal abuse from me. I apparently telephoned him at 3 in the morning asking where he was and accused him of not finishing a job off because he was too busy smoking. I have no recollection of this.

It all seemed so surreal like living in a different dimension. I was admitted to the ICU and remember feeling anxious and irritated. I remember my wife stood at my bedside crying and still I had little idea of what was occurring or where I was!

Thankfully, the care and the expertise of the ICU staff saw me through whatever I was experiencing. I was later told that I had serotonin syndrome and that it was quite rare for this to occur. I really do not remember much about the entire chain of events. I was happy that I came through it.

Learning points

- Fever in surgical patients is not always secondary to infection.

- Clinicians should be wary when patients are commenced on multimodal analgesia as inpatients. Specific care should be taken when prescribing tapentadol with other serotonergic agents due to an increased risk of serotonin syndrome.

- As part of a neurological examination, clonus is a useful clinical sign to be aware of when assessing for serotonin syndrome. levels when used at a therapeutic range. ${ }^{14}$ However, without any substantial evidence it is difficult to draw any conclusions in this case about whether the initiation of pregabalin played any part in the development of serotonin syndrome.

Tapentadol is a centrally acting opioid. It acts as a $\mu$-opioid receptor agonist, a norepinephrine receptor inhibitor and a weak serotonin uptake blocker in the rat. ${ }^{15}$ A review of post marketing safety data, undertaken by the tapentadol manufacturing pharmaceutical company, Grünenthal, concluded that it is unlikely that tapentadol has a clinically significant influence on the development of serotonin syndrome. ${ }^{16}$ Of the 151 cases identified, only 4 were deemed to be robustly diagnosed and of these other serotonergic medications were taken which could have caused serotonin syndrome. However, figures from the WHO VigiBase database rank tapentadol third on the list of serotonin syndrome individual case safety reports associated with an opioid alone or with another drug(s) (115 out of 1641 cases; 7\%), and second when the opioid was the only suspected cause (42 out of 147 cases; 28.6\%). ${ }^{15}{ }^{17}$ Following the administration of tapentadol at 00:30 a.m., the patient in this case suffered a considerable clinical deterioration which started around 04:44 a.m. As mentioned, this fulfilled the Hunter classification criteria and would therefore seem to strongly suggest that tapentadol, in combination with sertraline and amitriptyline, caused serotonin syndrome in this patient. Case reports exist of serotonin syndrome following tapentadol overdose, however this patient received just one dose of tapentadol. ${ }^{18}$

Prompt diagnosis in this case likely had a significant impact on the patient outcome, which illustrates the importance of keeping an open mind when clinical signs do not fully support the more commonly encountered presentation of sepsis. The key message to highlight here is that fever in a patient with serotonergic drugs should prompt a screening neurological examination. The most important sign to be aware of is clonus, be it spontaneous, inducible or ocular, as this has been found to be strongly associated with serotonin syndrome. ${ }^{4}$ Therefore, the presence of clonus with serotonergic polypharmacy should act as a red flag for clinicians.

Contributors MG obtained the case details and wrote the first draft of the case report. WDH re-drafted the case report and ensured the orthopaedic details in the case report were accurate. AC- $\mathrm{K}$ re-drafted the case report and ensured the critical care details of the case were accurate. GB offered insights into the pharmaceutical side of the case report and ensured the accuracy of the discussion around the different serotonergic medications included in the case report.

Funding The authors have not declared a specific grant for this research from any funding agency in the public, commercial or not-for-profit sectors.

Competing interests None declared.

Patient consent for publication Obtained.

Provenance and peer review Not commissioned; externally peer reviewed.

Open access This is an open access article distributed in accordance with the Creative Commons Attribution Non Commercial (CC BY-NC 4.0) license, which permits others to distribute, remix, adapt, build upon this work non-commercially, and license their derivative works on different terms, provided the original work is properly cited and the use is non-commercial. See: http://creativecommons.org/ licenses/by-nc/4.0/.

\section{REFERENCES}

1 Foong A-L, Grindrod KA, Patel T. Demystifying serotonin syndrome (or serotonin toxicity). Can Fam Physician 2018;64.

2 Nguyen CT, Xie L, Alley S, et al. Epidemiology and economic burden of serotonin syndrome with concomitant use of serotonergic agents. Prim Care Companion CNS Disord 2017;19.

3 Scotton WJ, Hill LJ, Williams AC, et al. Serotonin syndrome: pathophysiology, clinical features, management, and potential future directions. Int J Tryptophan Res 2019;12:117864691987392. doi:10.1177/1178646919873925 
4 Dunkley EJC, Isbister GK, Sibbritt D, et al. The Hunter serotonin toxicity criteria: simple and accurate diagnostic decision rules for serotonin toxicity. QJM 2003;96:635-42.

5 Boyer EW, Shannon M. Current concepts: the serotonin syndrome. N Eng/ J Med 2005;352:1112-20.

6 Werneke U, Jamshidi F, Taylor DM, et al. Conundrums in neurology: diagnosing serotonin syndrome - a meta-analysis of cases. BMC Neurol 2016;16:97.

7 Rosenberg H, Pollock N, Schiemann A, et al. Malignant hyperthermia: a review. Orphanet J Rare Dis 2015;10:1-19.

8 Atilla Ener R, Meglathery SB, Van DWA. Pain medicine volume 4, number 1, 2003 serotonin syndrome and other serotonergic disorders, 2003. Available: https:// academic.oup.com/painmedicine/article-abstract/4/1/63/1816666 [Accessed 31 May 2020].

9 Francescangeli J, Karamchandani K, Powell M, et al. The serotonin syndrome: from molecular mechanisms to clinical practice. Int J Mol Sci 2019;20:ijms20092288. doi:10.3390/ijms20092288

10 Marks DM, Patkar AA, Masand PS, et al. Does pregabalin have neuropsychotropic effects?: a short perspective. Psychiatry Investig 2009;6:55-8.
11 Lamberg JJ, Gordin VN. Serotonin syndrome in a patient with chronic pain polypharmacy. Pain Med 2014;15:1429-31.

12 Song H-K, Ho-Kyung S. Serotonin syndrome with perioperative oxycodone and pregabalin. Pain Physician 2013;16:E630-3 www.painphysicianjournal.com

13 Jellestad L, Stocker L, Jenewein J, et al. Serotonin syndrome after initiation of pregabalin on a stable regimen of antidepressant medication. Int J Med Pharm Case Reports 2016;7:1-4.

14 Luise Rao M, Vahlensieck M, Kr S. Gabapentin augments whole blood serotonin in healthy young men, 1988.

15 Baldo BA, Rose MA. The anaesthetist, opioid analgesic drugs, and serotonin toxicity: a mechanistic and clinical review. Br J Anaesth 2020;124:44-62.

16 Stollenwerk A, Sohns M, Heisig F, et al. Review of post-marketing safety data on tapentadol, a centrally acting analgesic. Adv Ther 2018;35:12-30.

17 Rickli A, Liakoni E, Hoener MC, et al. Opioid-Induced inhibition of the human 5-HT and noradrenaline transporters in vitro: link to clinical reports of serotonin syndrome. Br J Pharmacol 2018;175:532-43.

18 Walczyk H, Liu CHM, Alafris A, et al. Probable Tapentadol-Associated serotonin syndrome after overdose. Hosp Pharm 2016;51:320-7.

Copyright 2021 BMJ Publishing Group. All rights reserved. For permission to reuse any of this content visit

https://www.bmj.com/company/products-services/rights-and-licensing/permissions/

BMJ Case Report Fellows may re-use this article for personal use and teaching without any further permission.

Become a Fellow of BMJ Case Reports today and you can:

- Submit as many cases as you like

- Enjoy fast sympathetic peer review and rapid publication of accepted articles

- Access all the published articles

Re-use any of the published material for personal use and teaching without further permission

\section{Customer Service}

If you have any further queries about your subscription, please contact our customer services team on +44 (0) 2071111105 or via email at support@bmj.com.

Visit casereports.bmj.com for more articles like this and to become a Fellow 